\title{
Construction of Comprehensive Development Index and Analysis on the Development Trend of Solar Energy Industry
}

\author{
Linlin Jia, Xuehua Zhang*, Yahui Wu \\ Institute of Economics in Tianjin Polytechnic University, Tianjin, China \\ Email: d672084973@qq.com, ^xuehua671231@163.com
}

How to cite this paper: Jia, L.L., Zhang, X.H. and Wu, Y.H. (2018) Construction of Comprehensive Development Index and Analysis on the Development Trend of Solar Energy Industry. Engineering, 10, 477-485.

https://doi.org/10.4236/eng.2018.108033

Received: May 18, 2018

Accepted: August 3, 2018

Published: August 6, 2018

Copyright ( $\odot 2018$ by authors and Scientific Research Publishing Inc. This work is licensed under the Creative Commons Attribution International License (CC BY 4.0).

http://creativecommons.org/licenses/by/4.0/

\begin{abstract}
As a strategic emerging industry, solar energy industry has been wished to ease the energy crisis and stimulate economic growth. In order to judge the development of the industry objectively, this paper constructs the index system of China's solar energy industrial development from three dimensions of micro enterprise, medium industry and macroeconomic. This paper simultaneously takes 27 specific indicators, 54 listed companies and 10206 data from 2010 to 2016 as an example to calculate the industrial development index. The result reveals that with the implementation of the support policies playing a positive role in the development of China's solar energy industry, the solar industry has steadily improved. Solar energy industry in our country is under the support of national support policies and its technological innovation capability is relatively active. However, the moderate investment and financing activities and inadequate enterprise operational capacity, to some extent, alleviate the development of the solar energy industry. The above shows that the solar energy industrial development index and its evaluation methods can help people to accurately grasp the development trend of the solar energy industry and accurately identify the development of advantages and disadvantages.
\end{abstract}

\section{Keywords}

Solar Energy Industry, Development Index, Comprehensive Index Method, Analytic Hierarchy Process

\section{Foreword}

Under the circumstances of global warming, deterioration of the ecological environment and shortage of conventional energy, the new energy industry has 
received universal attention and support. The solar industry can not only ease the energy crisis, but also stimulate economic growth. Among the many new energy sources such as solar energy, nuclear energy, wind energy and biomass energy, solar energy industry, as a strategic emerging industry with its unique advantage, has become an important area of new energies.

Now, China's solar energy enterprises create nearly 1 million 600 thousand employment opportunities. And the solar power installed capacity of 77 million 420 thousand kilowatts increases by $81.6 \%$ over the previous year, retaining the most solar power installed capacity in the world. During the "12th Five-Year" period, solar power generation jumped from 260 thousand kilowatts to 43 million 180 thousand kilowatts, with an average annual growth of $177 \%$ [1]. The solar industry in China is yet in its infancy. Whether it can shoulder the responsibility of alleviating the energy crisis and stimulating the economic growth is still needed to be accurately grasped and comprehensively evaluated.

The research on the solar energy industry mainly focuses on the analysis of policy promotion [2] [3] [4], the role of technological innovation [5], and the role of market factors [6]. These single factor studies are indicators for the development index of solar energy industry. But mere these mentioned factors are not enough for an industrial perspective of the strong theoretical and empirical studies. The analysis of industrial operation efficiency [7], industrial performance evaluation [8] and industrial competitiveness evaluation [9] conduce to evaluate the development prospect of the industry from the aspects of operational efficiency, production efficiency and technological competitiveness. However, it still cannot concisely and objectively reflect the entire factors of the industry. Domestic and foreign literature search results show that the research on solar energy industrial development index has not been carried out yet.

Owing to the fact that solar energy industry has some similarities with culture industry [10], manufacturing industry [11], modern service industry [12], high-tech industry [13] and other industries, and that these industries already have some mature research achievements, this paper refers to the research results of these industrial development indices in the process of constructing the "Solar Industry Development Index". It takes comprehensive perspective of self-sustaining ability of micro enterprises, medium industrial structure and macroeconomic development factors into consideration, and then takes 54 solar energy listed enterprises as an example to measure the development index for the sake of providing reference for enterprises and management institutions.

\section{Research Method}

The index is an index reflecting the trajectory of the same thing in different periods, and is used to measure the relative number of changes in one variable to another specific variable. As an important statistical method to analyze the quantitative changes in social economic phenomena, the development index could comprehensively reflect the change direction and degree. The develop- 
ment index is generally based on a specific period. And its base number is 1 or 100.The original data during the inspection period divides the original data during the reference period, and then multiplies by the base number, that is, the development index of the field during the inspection period [14]. This paper sets 100 as base number.

\subsection{Construction of Index System}

In this paper, the index system of solar energy industrial development is sifted from three dimensions: micro enterprise, medium industry and macroeconomic. The index system of China's solar energy industrial development is divided into four diverse parts, that is, the development index layer, the first level index layer, the secondary index layer and the specific index layer. The basic framework is shown in Table 1.

\subsection{The Measure of Development Index}

\subsubsection{Standardization of Specific Index}

Standardized processing of raw data aims to eliminate the effect of raw data on

Table 1. The index system of solar energy industrial development.

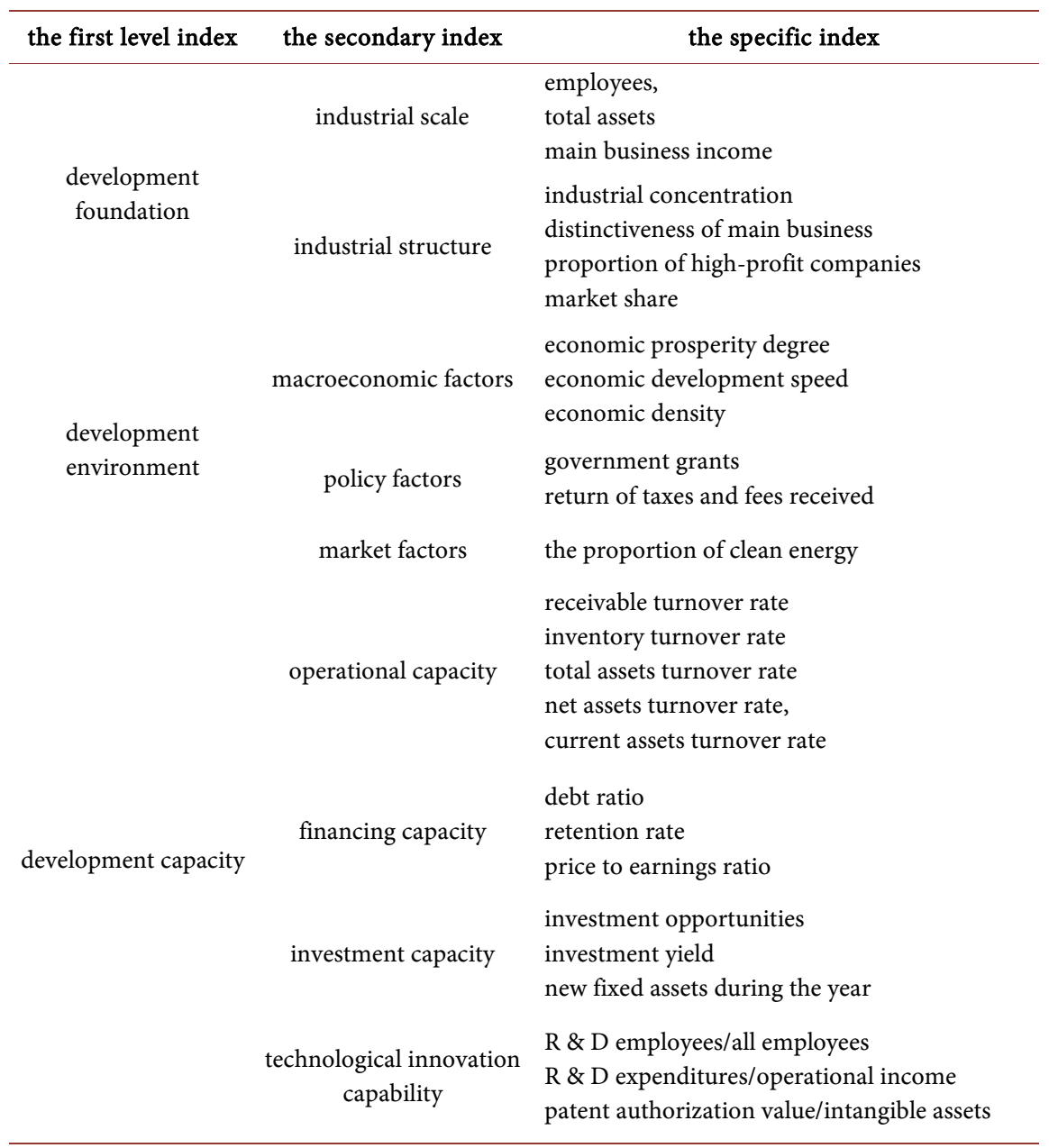


the order of magnitude. In order to reflect the dynamic characteristics of the development index, in the standardization course, the original data was processed by the ratio method, which divides the value of the inspection period by that of the reference period.

$$
V_{i}=X_{i t} / X_{i(t-1)}
$$

Among them, $V_{i}$ is the normalized value of the $i-t h$ index. $X_{i t}$ is the value of the $i$-th index in the $t$-phase (the value of the observation period). And $X_{i(t-1)}$ is the value of the $i$-th index in the $t-1$ period (The base period value).

\subsubsection{Weight of the Index}

The first level index is weighted by AHP [15], while the secondary index and specific index are weighted by equal rights method [16]. The detailed procedures are as follows.

The first step is to establish a hierarchical structure model. The index involved in the evaluation are divided into four levels, namely, the development index layer, the first level index layer, the secondary index layer and the specific index layer.

The second step is to build a judgment matrix. Construct a judgment matrix for the secondary indicators as formula (2) shown. Afterward, compare the factors of the same layer with each other. After that, score according to the significance by 1 to 9 . Set the judgment matrix to $A=\left(a_{i j}\right)_{n \times n}$

The third step is to calculate the weight according to expert consultation. Mathematical models are needed to rank the consistency judgment matrix filled by experts. And then calculate the relative weights of each factor in each matrix. For the consistency judgment matrix, each column is normalized to the corresponding weight. While for the non-consistent judgment matrix, each column is normalized to its approximate corresponding weight.

The fourth step is to test the consistency. First, calculate consistency index CI.

$$
C I=\frac{\lambda_{\max }-n}{n-1}
$$

Among them, $\lambda_{\max }$ is the maximum eigenvalue of the matrix $A, \mathrm{n}$ is the order of the matrix

After that, utilize MATLAB program to get the maximum eigenvalue of the matrix. Afterward, calculate the corresponding mean random consistency $R I$ [17], and then the consistency ratio $C R, C R=C I / R I$. It is generally accepted that when $C R<0.1$, the consistency of the judgment matrix is acceptable.

The fifth step is to confirm the weight of the index. For the weight of the first and secondary index, on the basis of the Delphi questionnaire survey, the geometric mean method [18] is used to count the questionnaire through the validity test. And for the specific index, the equal rights method is used due to its amount [19]. 


\subsubsection{Calculation of the Index}

Based on the standardized data and the weight of the specific index, the comprehensive index method is applied to calculate the index of China's solar energy industrial development. The formula is as follows.

$$
S D I=\sum W_{I} \cdot V_{i}
$$

Among them, $S D I$ is the index of China's solar energy development, $W_{i}$ is the weight of $i_{t h}$ index, and $V_{i}$ is the standardized value of $i_{t h}$ index.

\section{Empirical Analysis-Taking 54 Solar Energy Industry Listed Companies as an Example}

\subsection{Sample Selection and Data Sources}

It is accessible to get the data of the solar energy industry listed companies, whose market sensitivity and policy sensitivity are high. The solar industry development index is measured by the sample. In the macro, it can be used as a barometer for the development of solar industry in China to reflect the development trend. Moreover, in the micro, it can reflect the development trend of a single enterprise. Based on the SFC industry and CITIC securities industry, this paper selects 54 solar energy industry listed companies from 323 listed companies in Shanghai and Shenzhen A shares as data samples.

The micro-data comes from the enterprise accounting annual report, and the macro-data come from the national research network and the national statistical yearbook.

\subsection{Evaluation of the Solar Energy Industrial Development}

\subsubsection{Index Standardization}

According to formula (1), the standardization of specific indicators is carried out.

\subsubsection{Determination of Weight}

The weight of index is determined by questionnaire from expert, including solar energy experts, economists, entrepreneurs, government officials and the public. There were nearly 200 questionnaires issued in 3 rounds, and only 59 questionnaires pass through consistency check. The geometric mean method was used to conduct the survey result statistics. The statistical results were input into the judgment matrix, and the weight of the secondary index is calculated by R software. The result is shown in Figure 1.

\subsubsection{Evaluation of Index}

According to the index system of the solar energy industrial development and the annual report data of 54 solar energy listed companies in China for 2010-2016 years, the development index of solar energy industry in 2011-2016 of China is calculated. In order to facilitate the horizontal comparison and more intuitionistic reflection all index and the influence on the overall development trend of the solar energy industry, the figures are drawn as follows. 


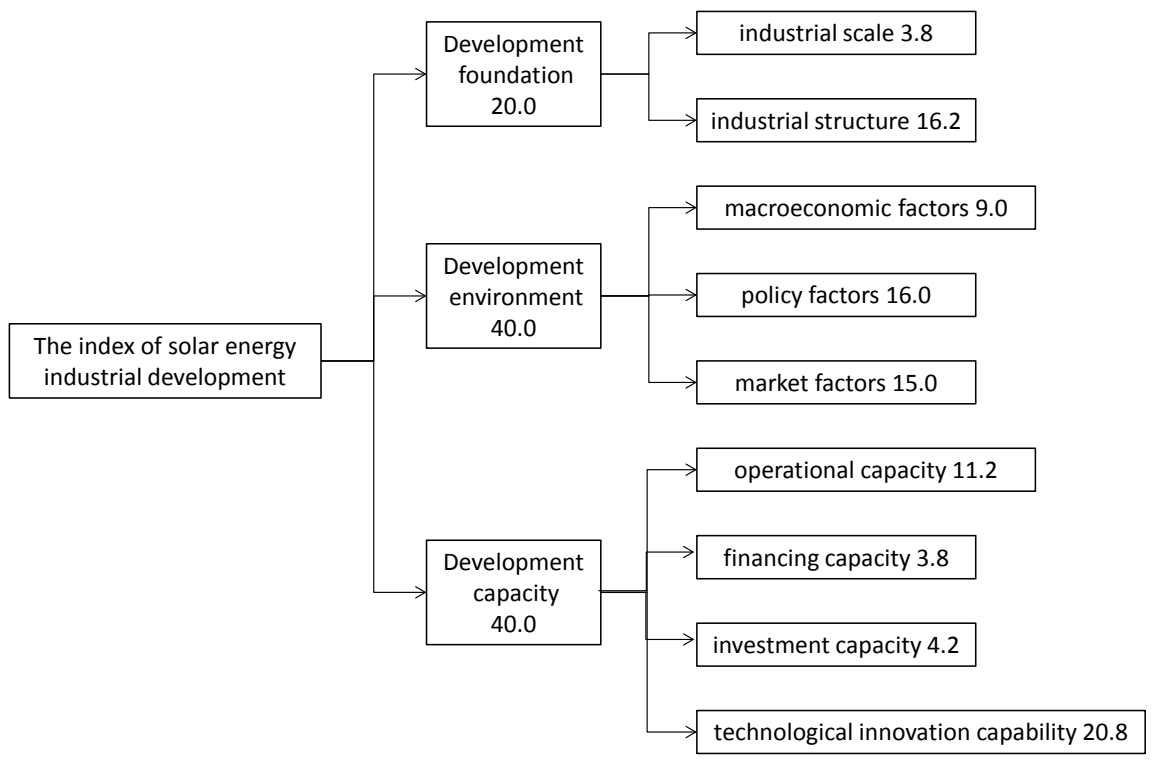

Figure 1. Weight of solar energy industry index.

From Figure 2, we can figure out that the curves of comprehensive development index and the development capability are roughly the same.

From Figure 3, the development foundation is mainly influenced by industrial structure, while the industrial scale tends to be stable.

From Figure 4, the development environment is composed of three factors, macroeconomic, policy and market. The trend of macroeconomic and policy factors shows that the macroeconomic and policy support is inversely proportional. As a whole, the trend of the development environment is strongly influenced by the policy factors.

From Figure 5, the curves of the development capability and the financing capacity are almost similar. It can be said that the financing ability is the indicator of the development capability. There is a slight fluctuation in operating capacity, and its trend is improving. The same trend of investment capability and technological innovation capability has a certain pulling effect on development capability.

\section{Conclusions}

By measuring the development index of the solar energy listed companies and analyzing the calculation results, there are a couple of results as follow.

1) The development of solar energy industry is steadily improved under the positive influence of the industrial development foundation, the development environment and the capacity.

2) In the case of the overall slowdown in economic growth, the solar energy market has also been affected, but with the implementation of the supporting, which has a positive effect on the development of the solar industry in China, it also creates new opportunities for the future development.

3) While the enterprises are paying attention to the growth of scale, the 


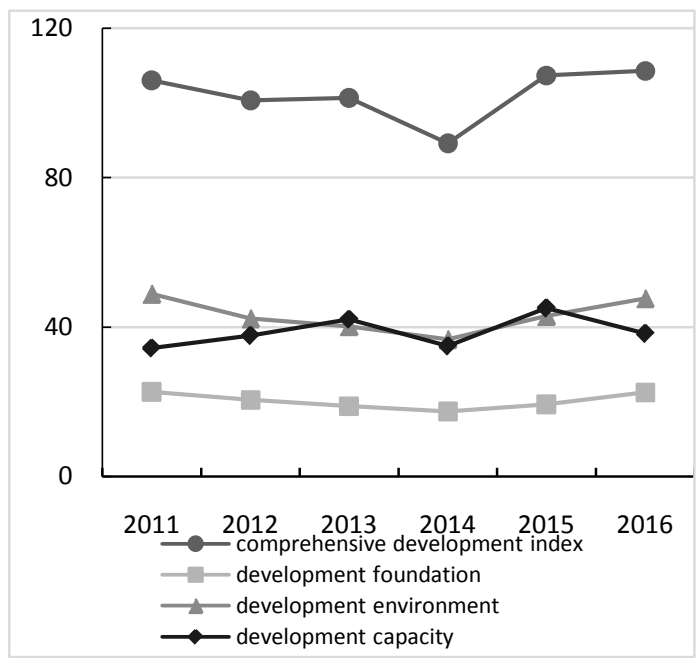

Figure 2. Comprehensive development index and its first index trend in 2011-2016.

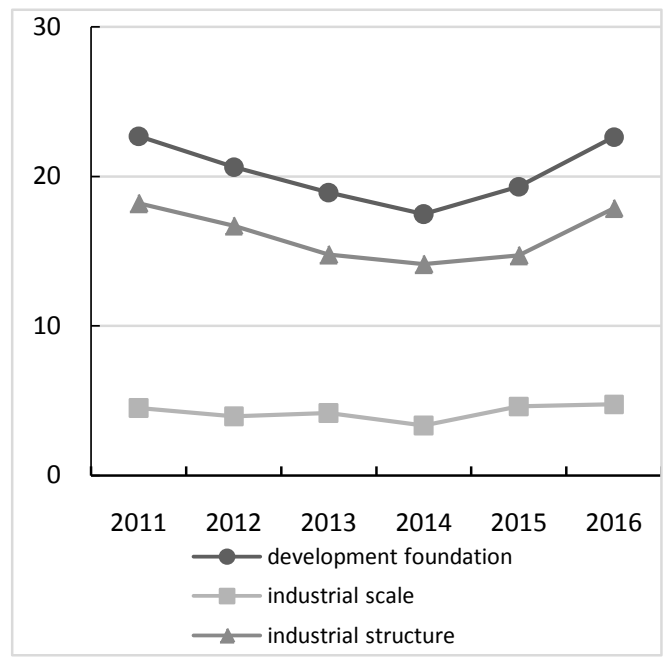

Figure 3. Development foundation its secondary index trend in 2011-2016.

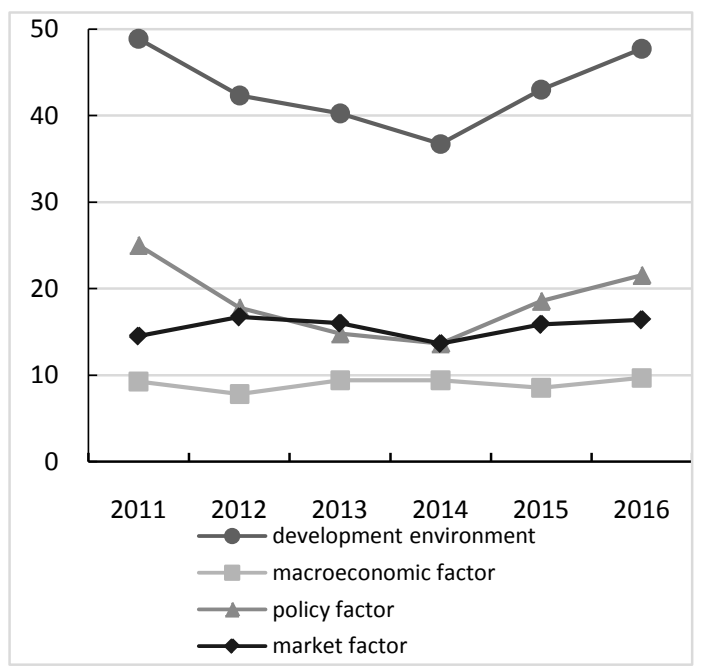

Figure 4. Development environment and its secondary index trend in 2011-2016. 


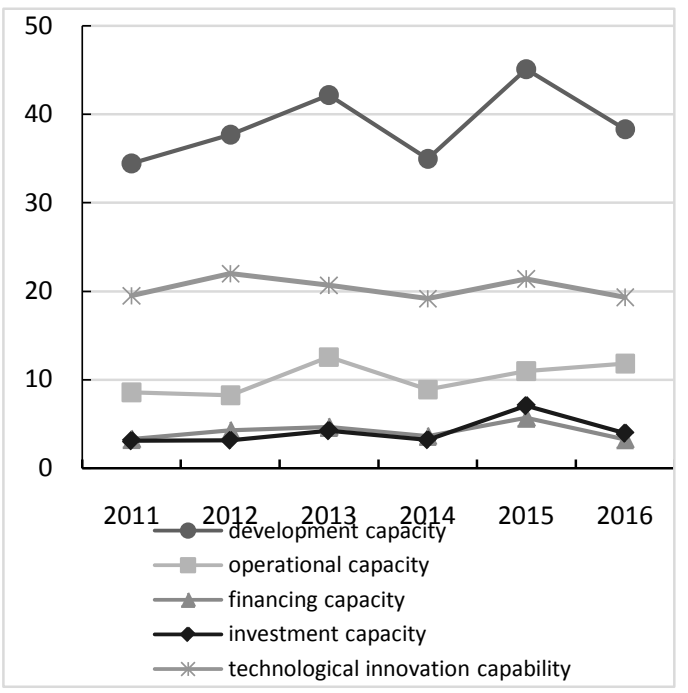

Figure 5. Development capacity and its secondary index trend in 2011-2016.

enterprises should also strengthen the fine management and improve their operating ability. Meanwhile, the national policy support should be used to strengthen the technological innovation and its own development ability.

To sum up, the sound development of the solar energy industry not only needs to strengthen the fine management themselves, improve the technological innovation, but also needs a good environment for development. Only by the common role of both inside and outside can the solar energy industry in China continue to move forward.

\section{Research Project}

National Social and Science Fund-Research on green development evaluation and planning system based on "total carbon" (18BJY079); Beijing Financial project-Study on optimization and upgrading of traditional high energy consumption industry and cultivation of new green industry in Beijing, Tianjin and Hebei (PXM2018_178216_000002_00299336_FCG-Innovation Engineering-Pre-research).

\section{Conflicts of Interest}

The authors declare no conflicts of interest regarding the publication of this paper.

\section{References}

[1] Ministry of Planning and Development of the China Electric Power Enterprise Federation (2017) National Electricity Supply and Demand Situation Analysis and Forecast Report in 2016-2017. Electrical Appliance Industry, No. 02, 11-16.

[2] Winter, B. (2011) Economic Analysis of Government Subsidies for Solar Photovoltaic Industry. Price Monthly, No. 5, 73-76.

[3] See, Y. (2013) Research on the Policy Effect of China Solar Photovoltaic Industry. Liaoning University, Shenyang.

[4] Yang, J. and Liu, Y.C. (2012) Research on the Policy Support of China's New Energy 
Industry-Based on the Analysis of the Price Theory and Practice Based on the Development of Solar Photovoltaic. Wind Power and New Energy Automobile Industry, No. 5, 72-73.

[5] Teng, F., Liu, Z.G., Liu, Y., et al. (2013) The Technological Innovation Ability and Competitive Situation of China's Solar Energy Industry-Based on the Perspective of Patent Information Analysis. Economic Problems, No. 11, 84-90.

[6] Hu, X.H., Chen, L.Z. and Jiang, S.Y. (2015) Strategic Emerging Industries Encountered the Impact and Prevention of Trade Restrictions Measures-Taking the Solar Cell Industry as an Example. Economic Problems, No. 2, 133-139.

[7] Wang, Y.H. and Liu, S.F. (2015) Performance Evaluation of H Photovoltaic Company Based on Efficacy Coefficient. Finance and Accounting, No. 8, 25-28.

[8] Fu, R., James, T.L. and Woodhouse, M. (2015) Economic Measurements of Polysilicon. IEEE Journal of Photovoltaics, 5, 515-524.

[9] Xu, Z.Q. (2002) Investigation and Analysis of Soybean Production and Circulation Costs in Heilongjiang Province. China Food and Nutrition, No. 06, 28-32.

[10] Zhou, F.X. (2008) Research on Development Index of China's Manufacturing Industry. Statistics and Decision Making, No. 19, 46-48.

[11] Wang, J., Lu, C., Guo, Z., et al. (2015) An Empirical Study on the Quality Development Index of Multinational Manufacturing Industry and Its Changing Law. Progress and Countermeasures in Science and Technology, No. 18, 43-50.

[12] Han, S.T. (2014) Construction and Improvement of China's Service Industry Price Index System. China Statistics, No. 6, 9-11.

[13] Yang, Q., Duan, X.J., Zhang, W., et al. (2014) Analysis of the Development of the Development Level of China's High and New Technology Industry and Analysis of Its Influencing Factors. Resources and Environment of the Yangtze River Basin, 23, 1649-1658.

[14] Li, F.Z. (2011) Principles of Statistics. Dongbei University of Finance and Economics Press, Dalian, 123-128.

[15] Yang, L.Q. (2011) Prediction and Decision Making Method. Metallurgical Industry Press, Beijing, 175-177.

[16] Shi, Y., Chai, Y.Y. and Liu, Q.L. (2006) Evaluation of the Effectiveness of the Banking System. Journal of Harbin Engineering University, 27, 461-464.

[17] Jian, L.R., Liu, S.F. and Liu, Y. (2016) Prediction and Decision Soft Computing Methods and Applications. Electronics Industry Press, Beijing, 122-123.

[18] Dong, H. (2006) AHP in Post Evaluation of Water Conservancy Projects. China Rural Water Conservancy and Hydropower, 4, 88-89.

[19] Shi, Y., Chai, Y.Y. and Liu, Q.L. (2006) Evaluation of the Effectiveness of the Banking System. Journal of Harbin Engineering University, 27, 461-464. 